\title{
A importância da implantação do setor de projetos e obras no âmbito do corpo de bombeiros militar do Estado do Tocantins
}

The importance of implementing the projects and works sector in the context of the military fire department of the State of Tocantins

La importancia de implementar el sector de proyectos y obras en el contexto del departamento de bomberos militares del Estado de Tocantins

\begin{abstract}
Resumo
A necessidade de construir novas edificações, fez com que o comando do Corpo de Bombeiros Militar do Estado do Tocantins realocasse militares com formação em Engenharia Civil, para elaborar e aprovar processos de construção de quartéis e demais infraestruturas da corporação, visto que as edificações existentes não atendem às demandas da instituição. A equipe técnica é constituída de oficiais e praças que estão lotados em diferentes setores, não existindo setor específico de projetos e obras, acarretando desvio de funções, falta de equipamentos, "softwares", viaturas e material de consumo adequados. Os processos de obras públicas, diferentemente de obras particulares, devem seguir as exigências de legislações específicas, sendo assim obrigatória a elaboração de diversos documentos técnicos para a sua aprovação em órgãos de controle, de licitações e de fiscalização; porém nem sempre esses órgãos públicos do Estado, responsáveis pela elaboração de tais processos, estão disponíveis para atender à demanda da corporação, o que culmina no risco de perda de recursos que poderiam ser utilizados em novas construções ou em manutenções prediais; caso a instituição não possua setor técnico especializado com tais atribuições.
\end{abstract}

Palavras-chave: Obras públicas; Construção de quartéis; Processo licitatório.

\begin{abstract}
The need to build new buildings led the command of the Tocantins State Military Fire Department to relocate soldiers with training in Civil Engineering, to prepare and approve processes for the construction of barracks and other infrastructure of the corporation, as the existing buildings do not meet the demands of the institution. The technical team is made up of officers and enlisted personnel who are located in different sectors, with no specific sector of projects and works, resulting in diversion of functions, lack of equipment, "software", vehicles and adequate consumables. The processes of public works, unlike private works, must follow the requirements of specific legislation, thus being mandatory the preparation of several technical documents for their approval by control, bidding and inspection bodies; however, these public bodies of the State, responsible for the elaboration of such processes, are not always available to meet the corporation's demand, which culminates in the risk of losing resources that could be used in new constructions or building maintenance; if the institution does not have a specialized technical sector with such attributions.
\end{abstract}

Keywords: Public works; Construction of barracks; Bidding's process.

\section{Resumen}

La necesidad de construir nuevos edificios llevó al comando del Departamento de Bomberos Militares del Estado de Tocantins a reubicar a soldados con entrenamiento en Ingeniería Civil, a preparar y aprobar procesos para la construcción de cuarteles y demás infraestructura de la corporación, ya que los edificios existentes no cumplen con los requisitos. demandas de la institución. El equipo técnico está conformado por oficiales y personal alistado que se ubican en diferentes sectores, sin sector específico de proyectos y obras, resultando en desvío de funciones, falta de equipos, "software", vehículos y consumibles adecuados. Los procesos de obra pública, a diferencia de la obra 
privada, deben seguir los requisitos de la legislación específica, siendo obligatoria la preparación de varios documentos técnicos para su aprobación por los órganos de control, licitación e inspección; sin embargo, estos organismos públicos del Estado, encargados de la elaboración de dichos procesos, no siempre están disponibles para atender la demanda de la corporación, lo que culmina en el riesgo de perder recursos que podrían ser utilizados en nuevas construcciones o mantenimiento de edificios; si la institución no cuenta con un sector técnico especializado con tales atribuciones.

Palabras clave: Obras públicas; Construcción de cuarteles; Proceso de licitación.

\section{Introdução}

A missão do Corpo de Bombeiros Militar do Estado do Tocantins consiste em prevenir e realizar ações de combate a incêndios, salvamentos, resgates, segurança e proteção contra pânico; de proteção ao meio ambiente, e executar ações de defesa civil, para promover o bem-estar social e garantir a ordem pública do povo tocantinense (Cbmto, 2021). Para que essas missões sejam executadas da melhor forma possível, é fundamental que a corporação possua efetivo adequado e edificações com condições de salubridade, segurança e bem-estar, para que os militares possam descansar, se alimentar, executar a passagem de serviço e se preparar para o atendimento às ocorrências, devendo essas edificações atender à real necessidade $\mathrm{e}$ especificações para seu fim.

Para o deslocamento e atuação no atendimento às ocorrências, é necessária a utilização de viaturas, como Unidade de Resgate (UR), Auto Bomba Tanque (ABT), Auto Bomba Tanque Florestal (ABTF), Auto Escada, Auto Bomba Salvamento (ABS), Auto Tanque (AT), embarcações e demais viaturas que possuem alto custo de aquisição (milhões de reais) e alto custo de manutenção, devendo ser abrigadas em local seguro e protegido de intempéries.

Muitos são os equipamentos e materiais utilizados para o atendimento às ocorrências, como desencarcerador, cilindros de oxigênio e demais equipamentos de mergulho e salvamento aquático; cabos, mosquetões e demais equipamentos para salvamento em alturas; bomba costal, abafadores, sopradores para ocorrências relacionadas a queimadas e incêndios florestais; roupas de aproximação, capacetes, equipamentos de segurança e materiais de higienização. Todos esses itens citados devem ser armazenados em local devidamente adequado para evitar danos e perdas. Assim, por se tratar de uma instituição que presta atendimento a todos os tipos de ocorrências, seus militares devem estar em dia com o condicionamento físico, além de estarem sempre participando de treinamentos, para melhor atender à população. Para que melhor seja executado esse treinamento, são necessários infraestruturas como piscina, torre de salvamento em altura, academia, etc.

No Estado do Tocantins, existem quartéis do Corpo de Bombeiros Militar nas cidades de Palmas, Paraíso, Porto Nacional, Dianópolis, Araguaína, Colinas e Araguatins. Muitos desses quartéis não possuem instalações próprias, sendo abrigados em instalações cedidas pelas prefeituras dos municípios, não atendendo às reais necessidades para o fim a que são utilizadas, muitas vezes apresentando condições precárias de salubridade, higiene e, até mesmo, de segurança.

Obra pública é considerada toda construção, reforma, fabricação, recuperação ou ampliação de bem público. Ela pode ser realizada de forma direta, quando a obra é feita pelo próprio órgão ou entidade da Administração, por seus próprios meios; ou de forma indireta, quando a obra é contratada por terceiros por meio de licitação (Brasil, 2014).

Os trabalhos de fiscalização de projetos e obras públicas possuem particularidades diferentes das mesmas atividades relacionadas a obras particulares. Para todo o processo, devem ser observadas as normas e leis específicas para a contratação da empresa que prestará o serviço através do resultado de uma publicação de edital. É relevante salientar que os profissionais que atuam nessa área detenham conhecimentos das legislações vigentes; caso contrário, eles podem ser penalizados criminalmente por seus atos. A Administração Pública deve analisar o custo e o resultado final das obras públicas, que não podem ser onerosas, dada a limitação de recursos e a responsabilidade social do Poder Público, mas também não deve ter custo de obra excessivamente baixo, que venha desonerar o custo de seu uso, manutenção e conservação (Rbf, 2014). 
Na nova Lei de Licitações e Contratos Administrativos, criada em $1^{\circ}$ de abril de 2021, os contratos públicos passam a operar em uma nova legislação, que substitui as Leis n. ${ }^{\circ}$ 8.666/1993 (Lei de Licitações), 10.520/2002 (Lei do Pregão) e 12.462/2011 (Regime Diferenciado de Contratações - RDC), e aborda assuntos relacionados. Os órgãos públicos poderão optar entre a utilização da legislação antiga ou da nova, por dois anos; ao fim dos quais a nova Lei passará a ser obrigatória para todos (Cadip, 2021).

Deve haver planejamento de gastos públicos após a conclusão das obras. Pesquisas realizadas em vários países, para diferentes edificações, apontam que os custos anuais de operação e manutenção das edificações em uso variam entre $1 \%$ e $2 \%$ do seu custo inicial. Este valor pode parecer pequeno, porém, acumulado ao longo de anos, chega a ser equivalente ou até superior ao custo de construção (Abnt, 1999).

Apesar de a Secretaria de Infraestrutura, Cidades e Habitação do Estado do Tocantins (SEINF) possuir setores de projetos, orçamentos, fiscalização e licitação de obras públicas, esta atende todas as secretarias do Estado, não possibilitando dar a devida atenção às necessidades do CBMTO, pois há grande demanda para elaboração de novos processos institucionais de construção. Tal fato levou o comando da instituição a realocar militares com formação em Engenharia Civil, para trabalharem na elaboração de tais processos, além de dar apoio à licitação e à fiscalização das obras, porém esses militares estão lotados em setores distintos ao serviço por eles prestados.

Há uma problemática que compreende na falta de viaturas, equipamentos adequados, como "softwares" e computadores imprescindíveis para a elaboração de projetos arquitetônicos, complementares e planilhas orçamentárias, o que dificulta a elaboração das peças técnicas e aprovação de licenças e projetos, pois como não existe setor específico não há destinação de recurso para esse fim.

Atualmente, encontram-se em andamento diversos processos de construções e reformas de quartéis e outras infraestruturas elaborados por militares do CBMTO; como a construção do Quartel do Comando Geral, construção do centro de treinamento e reabilitação funcional, construção da piscina semiolímpica, construção do galpão de estacionamento de

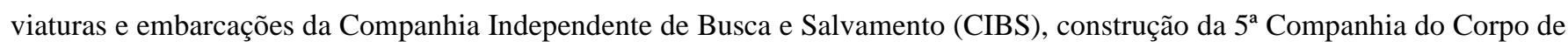
Bombeiros Militar, na cidade de Porto Nacional; reforma do antigo quartel do Comando Geral / Escola de Formação e Aperfeiçoamento de Bombeiros (EFAB) e construção de alojamentos no $1^{\circ}$ Batalhão de Bombeiro Militar.

E, por fim, deixam-se os seguintes questionamentos: há custo/benefício para o CBMTO, ao criar um setor específico de projetos e obras? É relevante para a instituição captar e aprovar recursos para construir, reformar e dar manutenções em seus quartéis e demais infraestruturas? As instalações e edificações existentes no CBMTO atendem à demanda da corporação? Vale a pena investir em viaturas, equipamentos e "softwares" específicos para elaboração e fiscalização de processos de construção?

\section{Metodologia}

O presente trabalho utilizou como metodologia de pesquisa qualitativa, o estudo teórico bibliográfico de manuais técnicos de controladorias gerais, tribunais de contas e Receita Federal, além de normas da Associação Brasileira de Normas Técnicas e legislações federais referentes a licitações e contratos de obras públicas. Foram realizados também estudos de caso de processos de construção que estão em andamento no CBMTO, observando-se os parâmetros adotados para elaboração dos documentos e peças técnicas compostas nos processos. Foram analisados "check-lists" utilizados por órgãos controladores e assessorias jurídicas da Secretaria de Infraestrutura, Cidades e Habitação do Estado do Tocantins, para conferência das exigências de documentação técnica dos processos a serem licitados e emissão de pareceres jurídicos. 


\section{Desenvolvimento}

Para concluir o objeto (obra) com eficácia, é necessário que se siga uma série de etapas, que antecipam o processo licitatório, que são fundamentais para o sucesso do empreendimento. Na figura 1, apresenta o fluxograma que procura demonstrar ao gestor, em ordem sequencial, as etapas a serem realizadas para a adequada execução indireta de uma obra pública. Tais etapas são importantes para se obterem todas as informações precisas e necessárias, para avaliar os riscos de prejuízos à Administração (Brasil, 2014).

Figura 1 - Fluxograma de procedimentos.

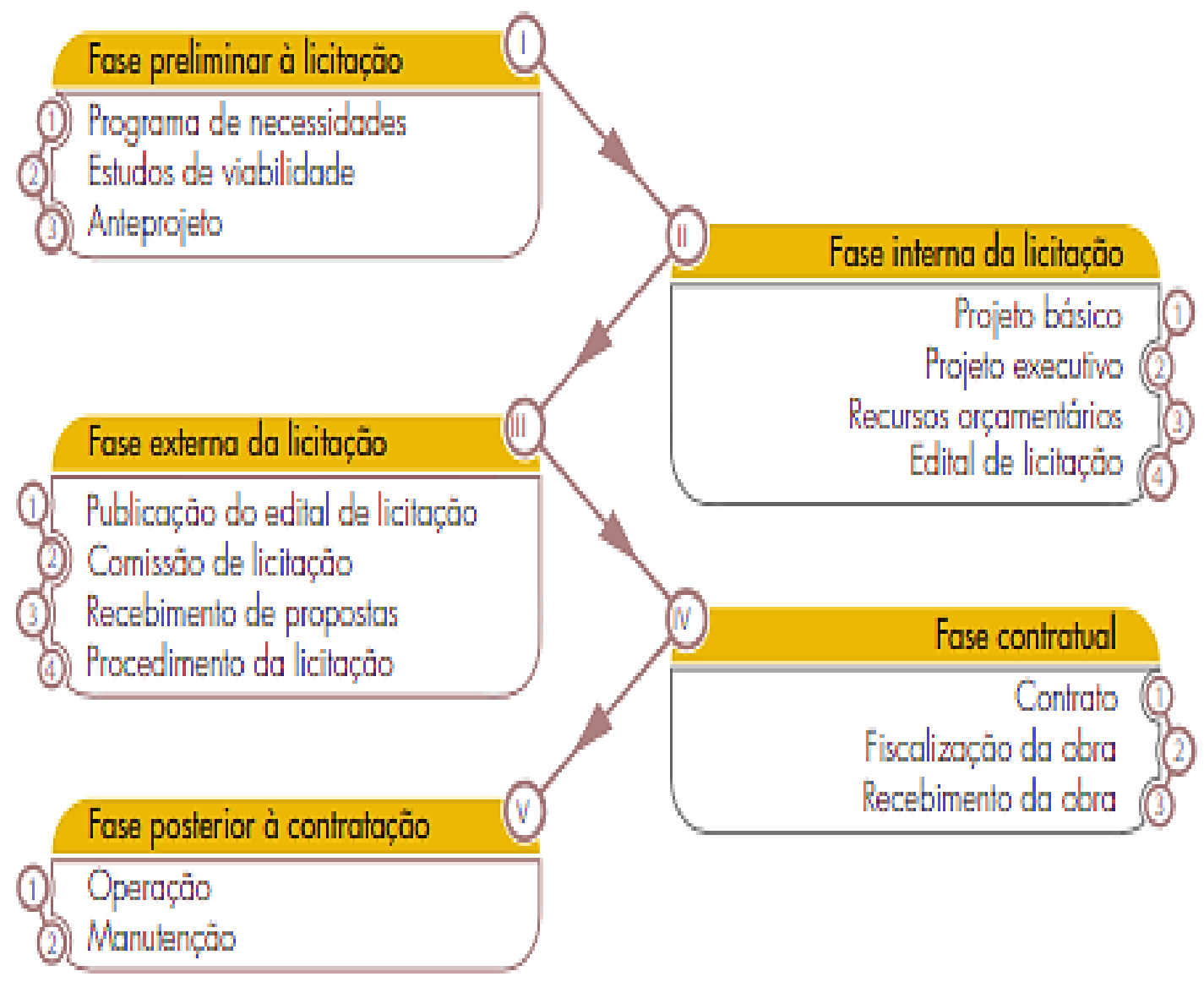

Fonte: Brasil (2014).

\subsection{Estudo de viabilidade/ estudo técnico preliminar (ETP) / anteprojeto}

Os estudos de viabilidade possibilitam a escolha do empreendimento que atendam aos requisitos especificados no programa de necessidades, sob os aspectos técnico, ambiental e socioeconômico (Brasil, 2014).O ETP consiste em documento da etapa inicial do planejamento de uma contratação para construção de uma edificação pública; este documento caracteriza o interesse público e a melhor solução, servindo como base para o anteprojeto e o projeto básico, caso conclua-se pela viabilidade técnica e econômica da contratação (Brasil, 2021).

O anteprojeto como o próprio nome já diz é um documento que antecede ao projeto, sendo um esboço, elaborado a partir de ETPs e das necessidades da contratante, buscando escolher a melhor solução técnica; estabelecendo as diretrizes e as necessidades técnicas adotadas na elaboração do Projeto Básico (CGE/AC, 2014). No decorrer da elaboração do ETP é que se avaliam as possibilidades de elaboração do anteprojeto, conforme as necessidades da Administração pública e as propriedades do objeto a ser licitado, ou contratado diretamente. 
O ETP leva em consideração a adequação técnica, funcionabilidade, requisitos ambientais, exigências das normas vigentes, necessidade de movimentação de terra decorrente da implantação da obra, execução de taludes, muros de arrimo e fundações especiais, processo construtivo a ser adotado, racionalização do processo construtivo, existência de fornecedores de materiais a serem empregados, estimativa de custo e viabilidade econômico-financeira do objeto (Nagalli, 2016; Siqueira, 2021).

Para a elaboração do ETP é importante que se tenha em mãos toda documentação oficial do terreno, constando suas medidas. É imprescindível que antes de iniciar qualquer processo de construção, sejam realizados ensaios de sondagem (para avaliar as características do solo e profundidade do lençol freático), e topografia do terreno, levantando-se as características planialtimétricas do terreno. Portanto deve haver previsão orçamentária para a aquisição de tais documentos.

\subsection{Projeto básico (PB)}

O Projeto Básico é a peça mais importante para a execução de uma obra pública de qualidade, que atenta às necessidades da Administração Pública e que traga benefícios à população, estabelecendo uma preconcepção do empreendimento. O PB é um conjunto de elementos precisos, suficientes e necessários, adequados para definir e dimensionar o objeto a ser licitado, elaborado com base nos estudos técnicos preliminares, que garanta a viabilidade técnica e o impacto ambiental (Brasil, 2021). O PB deve ser completo e, sem esse documento, não há legalidade na execução de obras públicas. É necessário a obtenção de licenças ambientais e aprovações de alvarás de construção para regularizar o empreendimento. No PB é realizada a estimativa do valor do objeto a ser licitado; em seguida, elabora-se o edital; e, posteriormente, ocorre a autuação do processo, indicação da fonte do recurso para custear as despesas e definição dos métodos e prazos de construção (Carvalho et al., 2017; Campos et al., 2019).

Os projetos devem ser elaborados por profissionais ou empresas legalmente habilitadas pelo Conselho Regional de Engenharia e Agronomia (CREA) ou pelo Conselho de Arquitetura e Urbanismo (CAU). Todas as peças de projetos e memoriais devem ser assinadas pelo respectivo profissional responsável, indicando o número das Anotações de Responsabilidade Técnica (ART) e Registros de Responsabilidade Técnica (RRT). Para a elaboração dos projetos devem ser consideras as exigências previstas nas legislações específicas aplicáveis a obras públicas, inclusive devem seguir as normas técnicas pertinentes (Brasil, 2014).

Os Projetos Complementares se referem aos Desenhos Técnicos secundários, sendo de grande importância, assim como o Projeto Arquitetônico, na caracterização do objeto a ser realizado. Em um processo de construção de uma obra pública, considera-se o desenho principal o Projeto Arquitetônico, porém é indispensável que também sejam elaborados os projetos complementares, como o Projeto de Estruturas e Fundações, Projeto de Prevenção e Combate a Incêndio e Pânico, o Projeto Hidrossanitário, o Projeto de Instalações Elétricas, Projetos de SPDA, Projetos de Cabeamento Estruturado, etc (CGE/AC, 2014).

É muito importante que se dê atenção especial aos projetos complementares, e que seja executada a compatibilização desses projetos, a fim de se evitarem problemas na execução do objeto, o que pode causar danos à obra e alteração no orçamento. Deve ser providenciada pela Administração Pública uma série de aprovações e autorizações: como o alvará de construção, autorização da vigilância sanitária (quando exigida), aprovação do projeto no Corpo de Bombeiros, aprovação do Órgão Ambiental, aprovação das concessionárias de serviços públicos (energia, telefonia, etc.). A responsabilidade por qualquer alteração nos projetos fica a cargo do autor do projeto. Independentemente da aprovação dos projetos, toda a responsabilidade legal relacionada às atividades profissionais é de inteira responsabilidade do autor do projeto (Brasil, 2014).

O orçamento-base, que é o orçamento elaborado pela Administração Pública, utilizado como referência na licitação, tem como objetivo servir de base para estabelecer critérios de aceitabilidade de preços totais e unitários no edital, sendo 
utilizado como referência para a análise das propostas das empresas participantes na fase externa do certame licitatório (Brasil, 2014). A memória de cálculo deve especificar a forma na qual calculou-se a quantidade de materiais e serviços que compõem a Planilha Orçamentária de Custo, devendo ser elaborada com base nos conteúdo dos Projetos Técnicos, Memoriais Descritivos e Memoriais de Especificações Técnicas (CGE/AC, 2014).

As especificações técnicas são necessárias para caracterização dos materiais empregados na construção do objeto e serve de base para fiscalização do contrato. Neste documento técnico ocorre a especificação dos materiais, equipamentos e serviços, visando ao desempenho técnico e à qualidade pré-definida e documentada, seguindo todas as especificações das normas técnicas e práticas construtivas, contendo materiais, equipamentos e serviços previstos no projeto (Brasil, 2014).

Outro documento necessário é o cronograma físico-financeiro, que permite melhor planejamento da obra, constando as etapas da obra, associando os custos da obra com os prazos demandados, possibilitando melhor gestão do andamento e fiscalização do contrato (Pires, 2014).

Para o estabelecimento do valor final da obra, é exigida a aplicação sobre o custo direto total da obra da taxa de Benefício e Despesas Indiretas (BDI ou LDI). Esse cálculo é efetuado através de fórmula, contemplando a remuneração da empresa executora do objeto contratado e suas despesas indiretas, o que garante risco e seguros, despesas financeiras, administração central e tributos. Trata-se de um percentual incidente sobre o custo total da obra, aumentando o valor final dos serviços. O valor do BDI pode ser divergente em casos específicos, como por exemplo equipamentos, e essas variações ocorrem em função do local, tipo de obra e sua própria composição (Brasil, 2014). É no projeto básico que se define a necessidade ou não da realização da vistoria no local da obra pelas licitantes; nele também apresentam as condições de recebimento da obra, obrigações da contratante e da contratada, procedimentos de fiscalização e gerenciamento de contrato, subcontratação e projeto executivo (Rbf, 2014).

\subsection{Projeto executivo (PE) / recursos orçamentários}

É no projeto executivo que se detalha toda a documentação técnica juntada no PB. É um conjunto de elementos que possibilitam a indicação precisa, qualitativa e quantificativa de todos os serviços, materiais, equipamentos necessários à execução da obra, contendo especificações técnicas de acordo com as normas técnicas (Brasil, 2021). O PE é um melhor detalhamento do $\mathrm{PB}$, não podendo sofrer alterações nas documentações de origem do processo, impedindo assim a descaracterização do objeto especificado no PB (CGE/AC, 2014). Para melhor entendimento, temos na Tabela 1, que demonstra a diferença dos níveis de precisão de cada projeto.

Tabela 1 - Nível de precisão de projetos.

\begin{tabular}{|c|c|c|c|}
\hline Precisão & Margem de Erro & Projeto & Elementos Necessários \\
\hline Baixa & $30 \%$ & Anteprojeto & $\begin{array}{ll}\text { - } & \text { Área a ser construída; } \\
\text { - } & \text { Padrão de acabamento; } \\
\text { - } & \text { Custo unitário básico. }\end{array}$ \\
\hline Média & 10 a $15 \%$ & Projeto Básico & $\begin{array}{ll}\text { - } & \text { Plantas principais; } \\
\text { - } & \text { Especificações básicas; } \\
\text { - } & \text { Preços de referência. }\end{array}$ \\
\hline Alta & $5 \%$ & Projeto Executivo & $\begin{array}{ll}\text { - } & \text { Plantas detalhadas; } \\
\text { - } & \text { Especificações completas; } \\
\text { - } & \text { Preços negociados. }\end{array}$ \\
\hline
\end{tabular}

Fonte: Brasil (2014). 
É necessário que o órgão contratante assegure o pagamento das medições das obras a serem executadas, devendo prever os recursos orçamentários específicos para serem executados no curso do exercício financeiro, de acordo com o cronograma físico-financeiro constado no projeto básico. Caso a execução da obra ultrapasse o exercício financeiro, a Administração não poderá iniciá-la sem prévia inclusão no plano plurianual, ou sem lei que autorize a inclusão, sob pena de crime de responsabilidade (Brasil, 2014).

\subsection{Licitação}

A Licitação é um de procedimento obrigatório ao qual a administração Pública deve se submeter previamente à celebração de um contrato de obra pública, assegurando igualdade de condições a todos que queiram realizar um contrato com o Poder Público, permitindo a identificação e escolha da proposta mais adequada ao interesse público, para posterior contratação (Meirelles, 2016).

Para o setor público, as obras e serviços de engenharia tornam-se uma prestação de fazer, pois o serviço é pago conforme a execução do objeto. A Administração Pública depende de etapas internas e externas da licitação, para garantir efetivo desempenho contratual de uma obra/serviço de engenharia (Rodrigues, 2017). O processo licitatório tem por objetivos: assegurar a seleção da proposta apta a gerar o resultado de contratação mais vantajoso para a Administração Pública, inclusive no que se refere ao ciclo de vida do objeto, assegurar tratamento isonômico entre os licitantes, bem como a justa competição, evitar contratações com sobrepreço ou com preços manifestamente inexequíveis e superfaturamento na execução dos contratos e incentivar a inovação e o desenvolvimento nacional sustentável. Na execução indireta de obras e serviços de engenharia, são admitidos os seguintes regimes: empreitada por preço unitário, empreitada por preço global, empreitada integral, contratação por tarefa, contratação integrada, contratação semi-integrada e fornecimento e prestação de serviço associado (Brasil, 2021).

Todas as informações necessárias para a elaboração das propostas pelas licitantes devem ser fornecidas pelas administrações, para que elas sejam elaboradas com total conhecimento do objeto da licitado, seja qual for modalidade escolhida. Na fase interna do processo licitatório, especifica-se o objeto a ser contratado, através do projeto básico, definindo as exigências mínimas para o recebimento de propostas dos licitantes, tornando assim uma etapa fundamental importância para o sucesso da obra pública (Brasil, 2014).

O edital de licitação é instrumento de grande importância no processo licitatório para contratação pública. Neste documento são mencionadas exigências para participação e aceitação das propostas das licitantes, trazendo informações como: as características da obra, os prazos da licitação, da construção e a forma de pagamento (Lima, 2019).

A administração deve exigir documentação que comprove que a qualificação dos concorrentes está de acordo com a obra que pretende contratar. Esses documentos devem ser analisados para saber se as empresas participantes do certame possuem habilitação exigida pela Lei de Licitações. O edital do certame deve trazer, em suas laudas, os critérios a serem utilizados no julgamento das propostas, com disposições claras e parâmetros objetivos; sendo que o mais comum escolhido para julgamento é a avaliação do preço global da proposta. Como deve ser atendido o princípio da publicidade, alcançando o maior número de licitantes, há a necessidade de publicação de avisos com o resumo dos editais (Brasil, 2014).

O objetivo da Comissão de Licitação é promover o processo licitatório em todas as suas fases, elaborando, publicando e divulgando o edital de licitação, prestando esclarecimentos aos licitantes, recebendo e analisando as propostas (Brasil, 2014). A melhor proposta é selecionada pela Comissão de Licitação, após disputa em que se garanta o tratamento igualitário entre as participantes. O contratado é obrigado a manter, por todo o prazo de execução do contrato, suas obrigações assumidas e todas as condições de habilitação e qualificação exigidas no processo licitatório (Costa, 2013). Após a homologação do resultado licitatório pela autoridade competente e adjudicação da obra licitada, é celebrado o contrato administrativo entre a contratante e 
a contratada. O contrato só tem validade se a Administração observar a ordem de classificação das propostas no procedimento licitatório, caso contrário, poderá submeter a nulidade do contrato (Brasil, 2014).

\subsection{Fiscalização de obra}

Para garantir que a obra executada siga todas as documentações apresentadas nesse artigo, é necessária a realização de atividades técnicas e administrativas, como a fiscalização da obra e do contrato; possibilitando assim garantir a execução do objeto, obedecendo às especificações, ao projeto, aos prazos estabelecidos e às demais obrigações previstas no contrato (CGE PB, 2014).

Diversas são as competências da fiscalização da obra, dentre elas temos: estabelecer diretrizes da contratada; emitir ordem de serviço para início dos trabalhos; quando necessário, interditar e determinar a paralisação da execução do contrato; recolher ART/RRT dos profissionais; acompanhar "in loco" a execução da obra com vistorias periódicas, emitir atestados e pareceres, conscientizar as autoridades situações irregulares, fazer anotações das ocorrências, glosar serviços não executados, aprovar e atestar medições realizadas, além de arquivar todos os documentos importantes como o termo contratual e todos os seus aditivos, planilha orçamentárias e formação de preços atualizada (Rodrigues, 2017).

Toda obra pública deve ter sua execução fiscalizada por 1 (um) ou mais fiscais do contrato, representantes da Administração, escolhidos conforme necessidades estabelecidas. É permitida, quando julgar necessário, a contratação de terceiros para assistir e subsidiar os fiscais, caso esses nomeados necessitem de auxílio técnico de equipe especializada. O fiscal do contrato deve anotar em registro próprio todas as alterações relacionadas à execução do contrato, sendo de sua competência determinar o que for necessário para a regularização de qualquer falha verificada. Ele deve informar a seus superiores, em tempo hábil para a adoção das medidas convenientes, a situação que demandar decisão ou providência que ultrapasse sua competência (Brasil, 2021; Silva et al., 2021).

É função do fiscal do contrato aplicar penalidades à contratada, pois é ele quem acompanha a execução do contrato e anota as deficiências e erros, em registro próprio; essas anotações serão de fato utilizadas para eventual aplicação de multas, infrações ou mesmo rescisão contratual. O agente administrativo nomeado para ser fiscal de contrato de um empreendimento público poderá responder por sua ação. Caso o fiscal do contrato não siga as legislações vigentes, ele poderá sofrer com ação culposa (negligência, imperícia, imprudência) ou dolosa, nas esferas cíveis (devendo ressarcir o dano), criminal (caso a conduta seja tipificada como crime), administrativa (nos termos do estatuto a que tiver submetido) e por improbidade administrativa (Costa, 2013; Chiaretto \& Carvalho, 2018).

\section{Resultados e Discussão}

Estão em andamento diversos processos de construção de quartéis e outras infraestruturas do CBMTO, elaborados por militares da instituição, dentre os processos que se encontram em estágios mais avançados temos:

\subsection{Construção do novo quartel do Comando Geral}

No ano de 2017, o CBMTO pleiteou recurso federal, proveniente do Ministério de Justiça e Segurança Pública, através da bancada federal parlamentar tocantinense, para a construção no novo QCG, no valor de R $\$ 11.601 .607,17$, sendo $1 \%$ desse valor referente à contrapartida da corporação. Tal recurso foi disponibilizado para todos os Estados da Federação, porém poucos optaram por utilizá-lo para construções, devido ao curto prazo de tempo para elaboração de toda documentação técnica necessária para aprovação, sendo que a maior parte das corporações optaram pela utilização do recurso para a aquisição de equipamentos, viaturas e armamentos. Vale ressaltar que o CBMTO não possuía terreno disponível para a construção; somente após a provação do recurso, foi disponibilizado o terreno pelo Governo do Estado do Tocantins. 
Foi montada uma força-tarefa por militares do CBMTO para a elaboração e aprovação do processo, contando com apoio de engenheiros e arquitetos não pertencentes ao efetivo da instituição, e o processo foi aprovado em dezembro de 2017 pelo Ministério de Justiça e Segurança Pública.

Sempre trabalhando com curtos prazos para entrega documental e por burocráticos trâmites de aprovação da Prefeitura Municipal de Palmas, Fundação Municipal do Meio Ambiente e Caixa Econômica Federal, nas quais ocorreram dezenas de análises e relatórios de correções. Inclusive, houve muitas dúvidas, até pelos mais otimistas, de que a obra realmente poderia ser concretizada.

Após aprovação por todos os órgãos relacionados ao processo, no ano de 2019, iniciou-se o processo licitatório no qual obteve-se a empresa vencedora do certame. No dia 14 de fevereiro de 2020, iniciou-se a construção em um terreno situado no Plano Diretor Sul de Palmas, capital do Tocantins, com $42.750 \mathrm{~m}^{2}$. Dentre as áreas a serem construídas, temos um bloco administrativo (Figura 2), com 3 pavimentos, com área de 3.320,13 $\mathrm{m}^{2}$. O prédio possui estrutura em aço, com claraboia, elevadores, piso em granito Itaúna branco e fachada envidraçada composta de vidro reflexivo "glazing".

Figura 2 - Maquete eletrônica do Bloco Administrativo do Novo QCG do CBMTO.

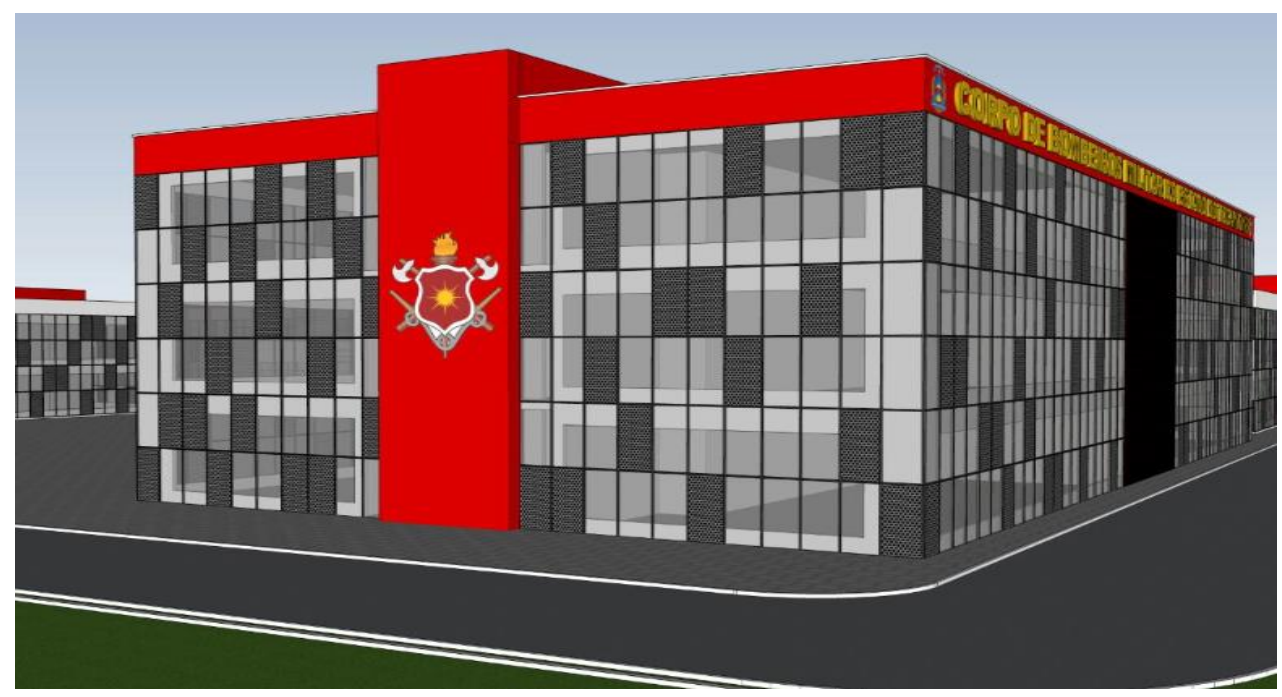

Fonte: Autor (2021).

Também está em construção uma guarita/alojamentos (Figura 3), sendo 3 (três) alojamentos (um masculino para praças, um masculino para oficiais e um feminino), com banheiros amplos, cozinha, sala administrativa e depósito de material de limpeza, possuindo área total construída de $237,66 \mathrm{~m}^{2}$. Será construído um pátio para formaturas, com vias asfaltadas que contornam o bloco administrativo. Está em andamento processo de aditivo para construção de um galpão para estacionamento de viaturas e um palanque para ser utilizado em cerimônias militares.

Apesar de o terreno da construção possuir grande valorização, visto que se encontra em uma das principais avenidas de Palmas, a avenida JK, o terreno apresentava-se bastante irregular, o que exigiu relevante serviço de nivelamento. 
Figura 3 - Maquete eletrônica da guarita/alojamentos do Novo QCG do CBMTO.

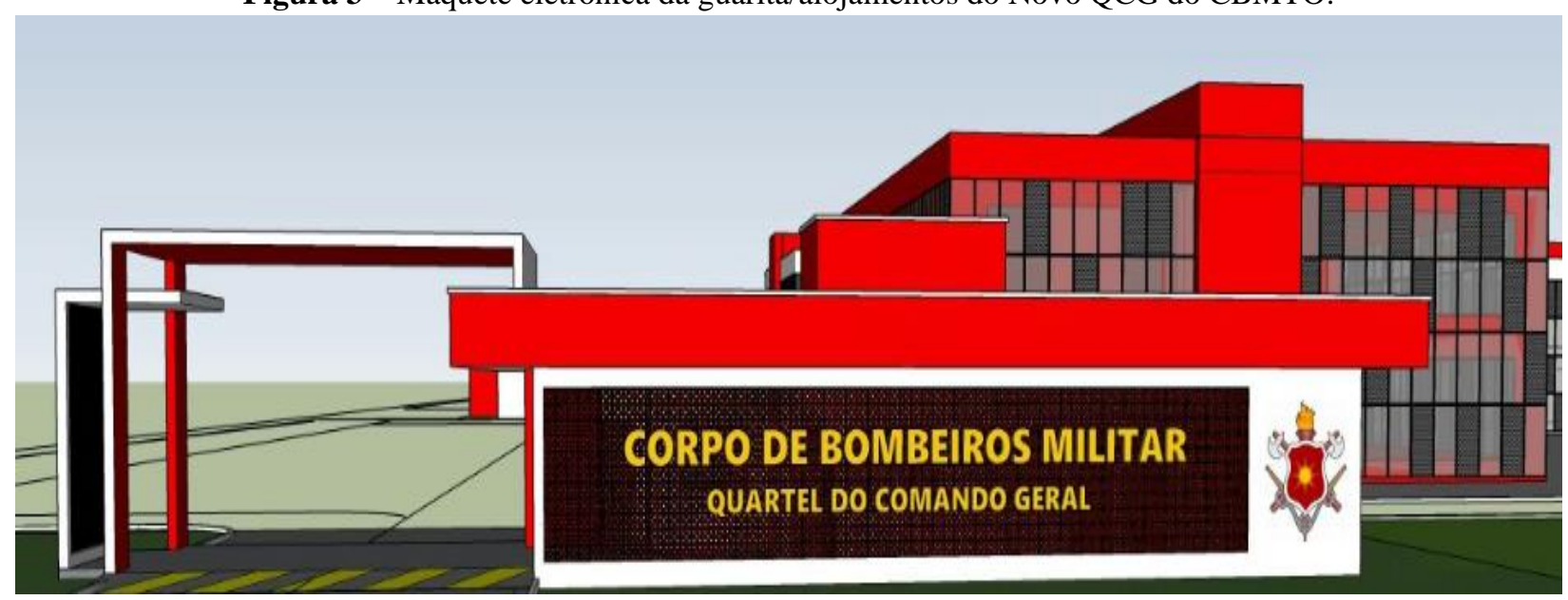

Fonte: Autor (2021).

Muitos foram os entraves após o começo da obra (Figura 4), como o início da pandemia de COVID 19 e necessidade de ajustes nos projetos e planilhas orçamentárias constadas no processo.

Figura 4 - Construção do bloco administrativo do Novo QCG do CBMTO.

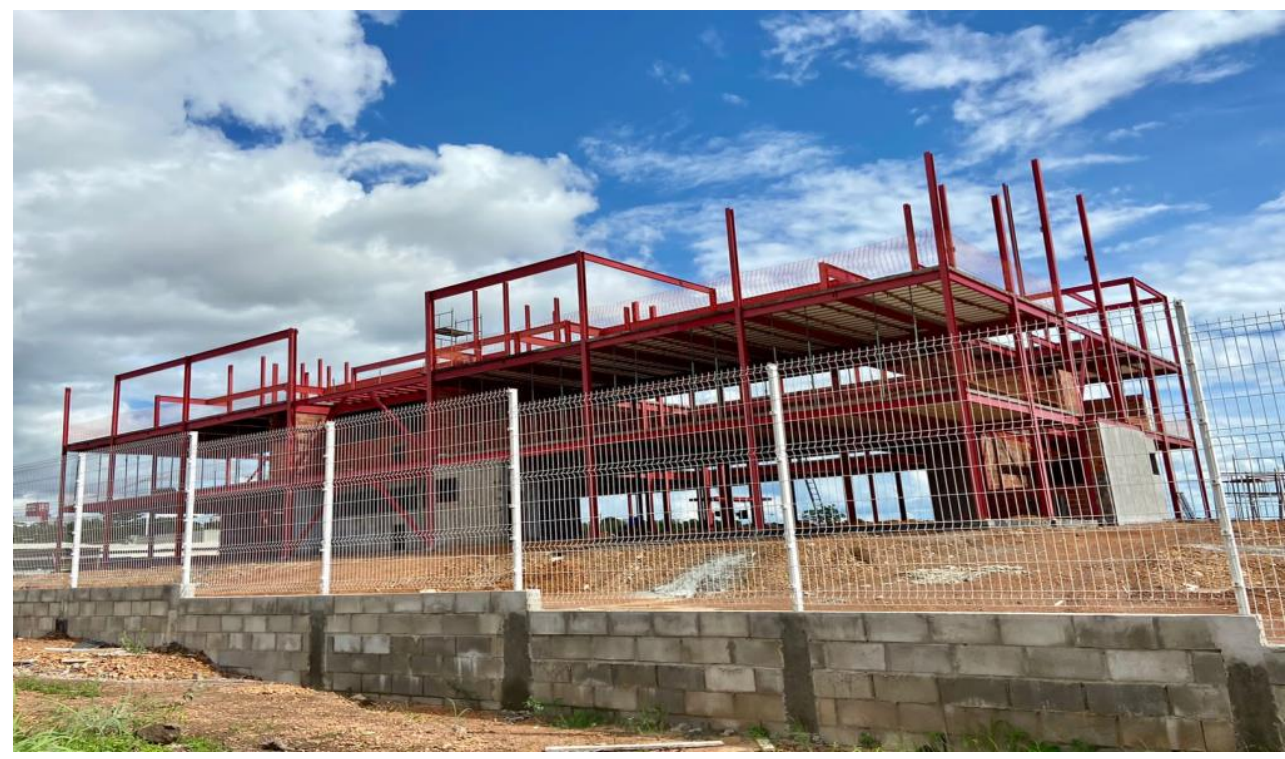

Fonte: Autor (2021).

A obra (Figura 5) encontra-se com 30\% de sua construção concluída, com o processo de reprogramação (aditivo) aprovado, e foram solicitadas pela construtora reajuste e reequilíbrio financeiro, estando prevista para ser finalizada no mês de março de 2022. Foi nomeado, oficial do CBMTO, fiscal do contrato da obra. 
Figura 5 - Construção da guarita/alojamentos do Novo QCG do CBMTO.

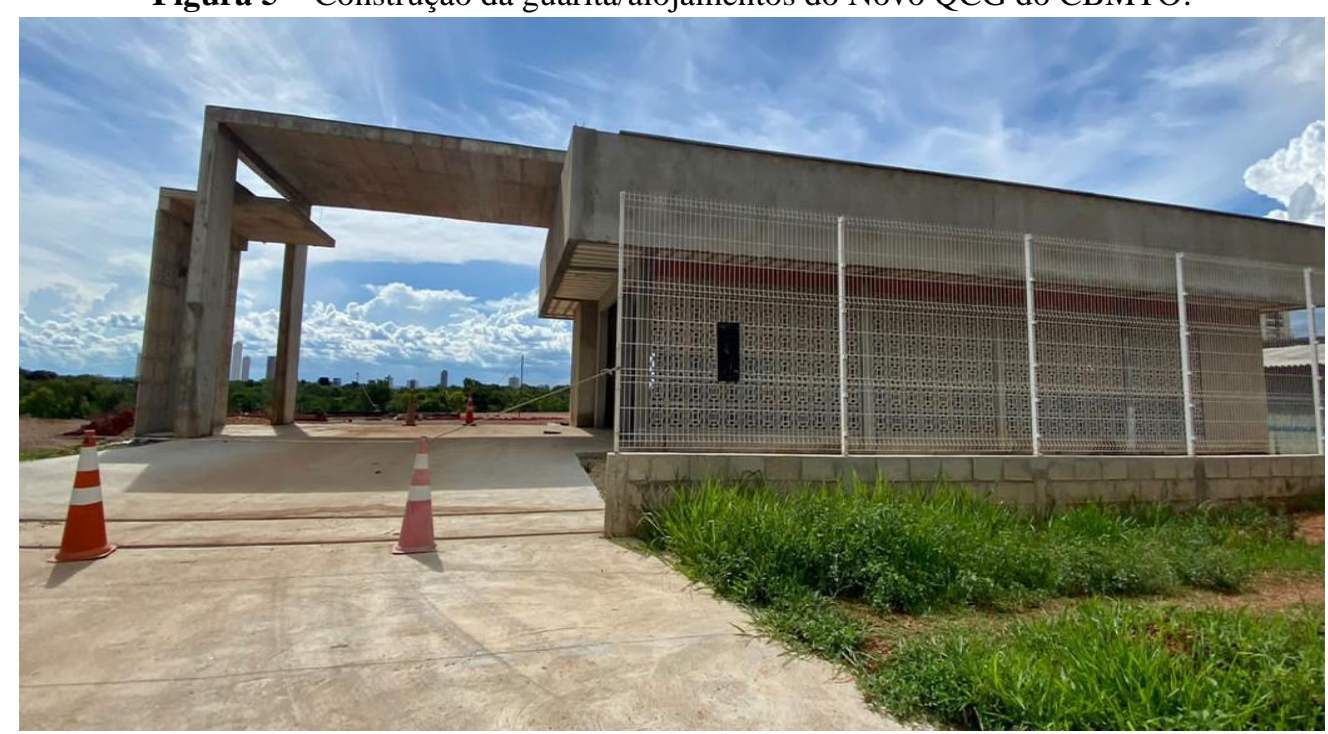

Fonte: Autor (2021).

\subsection{Construção da piscina semi-olímpica}

Será construída uma piscina semiolímpica nas dependências do antigo QCG do CBMTO. No mesmo terreno, encontra-se a Escola de Formação de Bombeiros, na qual a piscina será utilizada para realização de treinamentos, simulações de salvamento aquático, realização do teste de aptidão física e possivelmente será utilizada para escola de natação de atendimentos a civis.

Todo processo de construção foi elaborado, sendo a construção orçada em $\mathrm{R} \$ 726.697,16$, fonte de recurso da INFRAERO, tem prazo de construção de 6 (seis) meses, contados a partir da assinatura da ordem de serviço. A piscina possuirá as dimensões de $25,00 \mathrm{~m} \times 15,00 \mathrm{~m}$, contendo 6 (seis) raias (Figura 6). Será construída em concreto armado, com impermeabilização por argamassa polimérica, revestido com piso placa tipo porcelanato.

O revestimento do piso externo da área da piscina será antiderrapante, do tipo Fulget (granilite). Já estão previstos no processo todos os dispositivos hidráulicos, raias, blocos de partida e escadas de acesso. O processo encontra-se na Secretaria de Infraestrutura, Cidades e Habitação para publicação do edital de licitação. 
Figura 6 - Planta da piscina semi-olímpica do CBMTO.
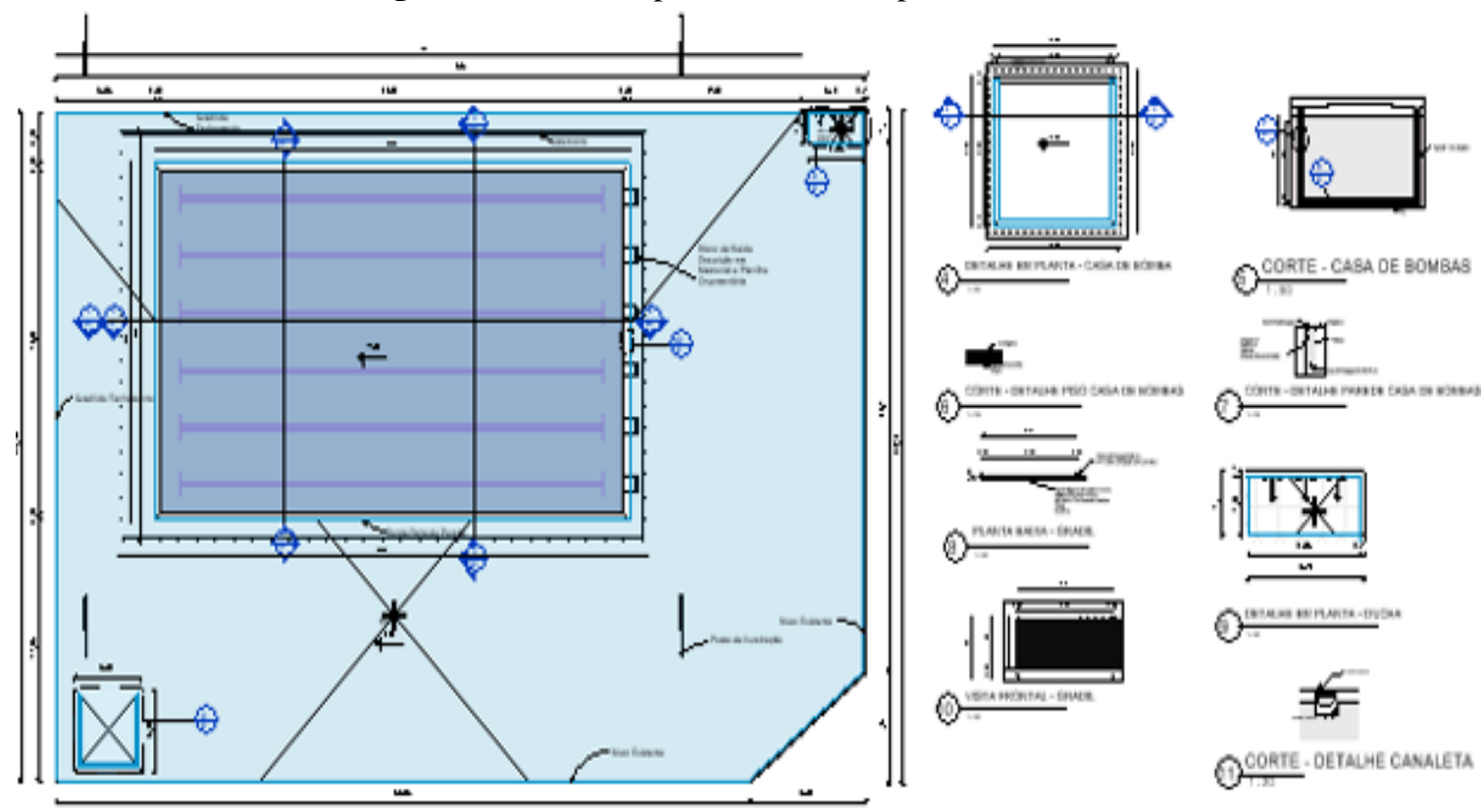

CPLANTA BAIXA. DECX
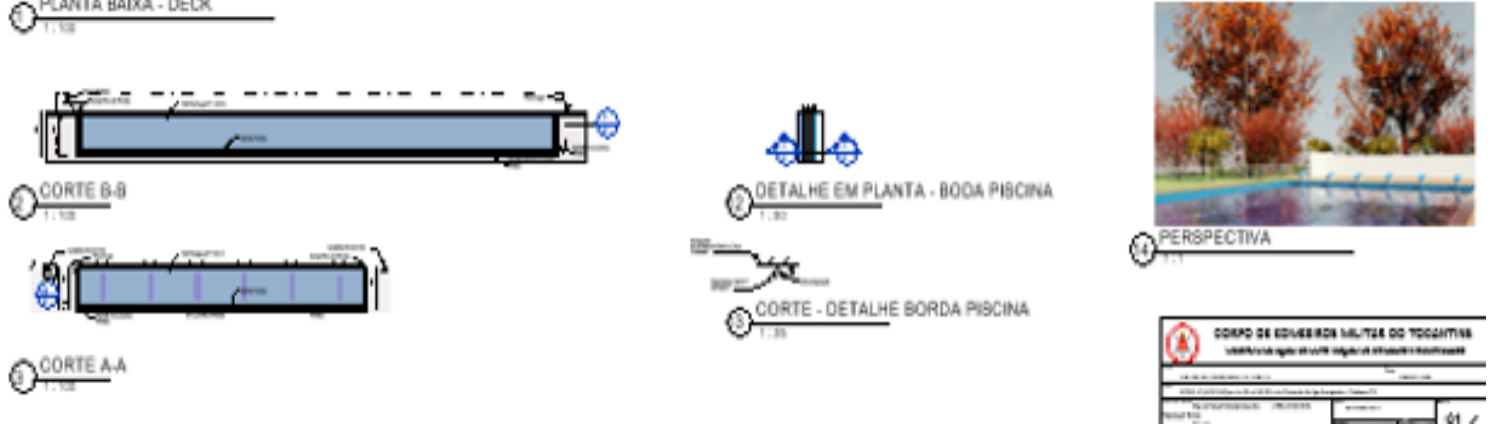

Fonte: Autor (2021).

\subsection{Reforma do antigo QCG / Escola de Formação de Bombeiros (EFAB)}

O antigo QCG do CBMTO está construído desde os primeiros anos da cidade de Palmas, visto que se trata das instalações do antigo Aeroporto de Palmas. Na mesma edificação, encontra-se a EFAB, que é local de realização de cursos da instituição.

Há alguns anos, a edificação vem sofrendo com manifestações patológicas causadas pela infiltração das águas das chuvas, o que causou danos a equipamentos elétricos, instalações elétricas, forro de gesso e corrosão de pilares metálicos. Tais problemas culminaram na necessidade de uma reforma, cujo processo se encontra finalizado e sua publicação de licitação já efetivada. A obra é prevista para finalizar em 3 (três) meses a partir da data de assinatura da ordem de serviço. Obra licitada no valor de $\mathrm{R} \$ 370.545,19$, com fonte de recurso da INFRAERO (Figura 7). 
Figura 7 - Planta da reforma do antigo QCG do CBMTO.

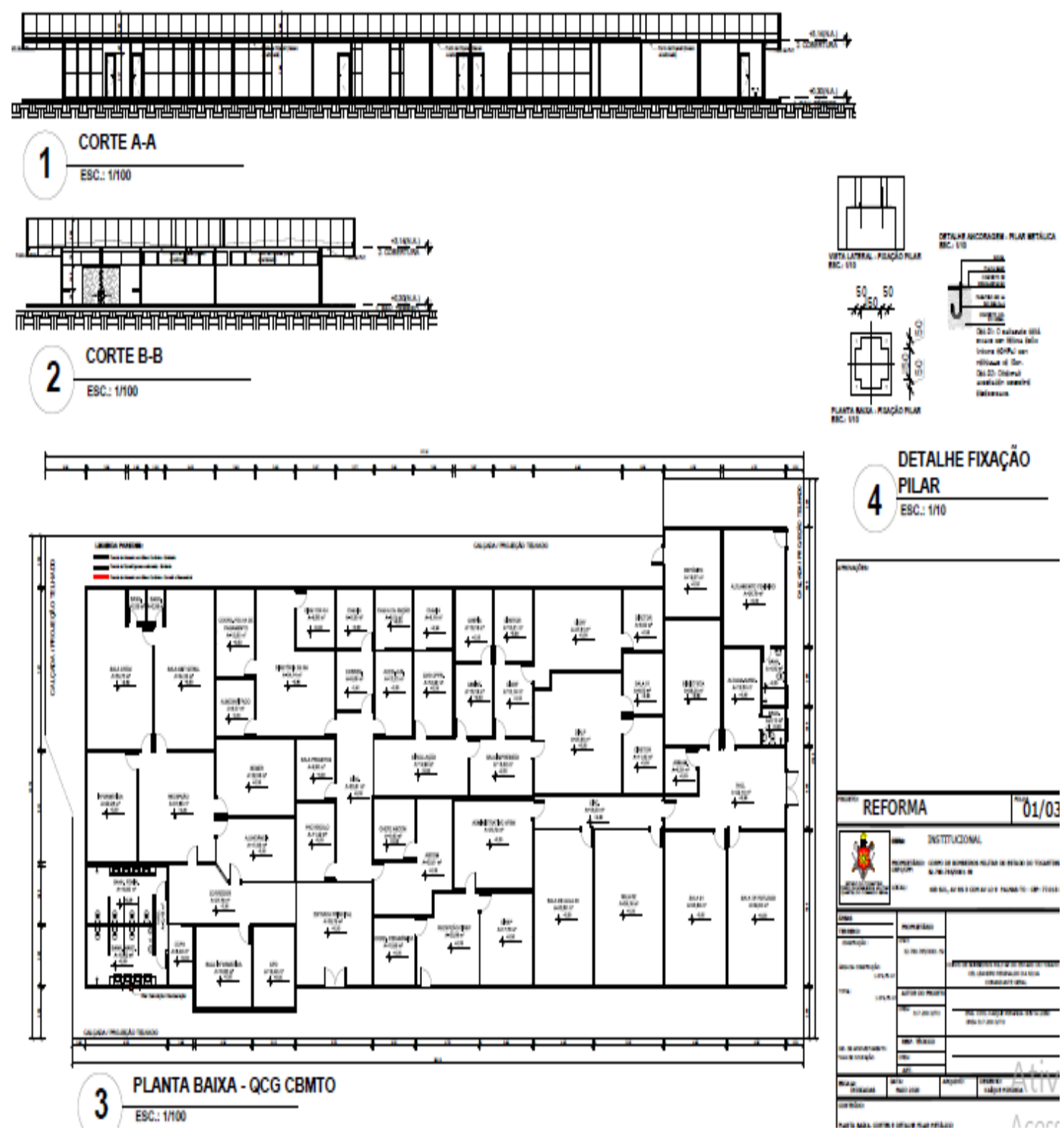

Fonte: Autor (2021).

\section{Conclusão}

É de grande importância a criação de setor específico de projetos e obras no CBMTO, pois essa equipe será responsável pela aprovação de recursos de construção de novos quartéis e infraestrutura da corporação, considerando um efetivo pequeno de militares comparados aos resultados obtidos com construções em andamento orçadas em mais de 14 (quatorze) milhões de reais. Diversas são as atribuições da equipe técnica que trabalha no planejamento, elaboração de projetos e demais documentos técnicos de engenharia, participação nas aprovações e licenças necessárias, e até a participação nos processos licitatórios e fiscalização de obras, necessitando assim de recursos próprios para pagamento de taxas, realização de ensaios e levantamentos, material de consumo administrativo e viaturas para deslocamentos necessários ao bom andamento dos processos.

Como algumas edificações existentes do CBMTO não atendem às necessidades e demandas da corporação, há necessidade imediata de se iniciarem novos processos de construção, para ampliação, reforma e manutenção, ou até mesmo de novas construções. 


\section{Referências}

ABNT. (1999). Associação Brasileira de Normas Técnicas, NBR 5674: Manutenção de Edificações - Procedimento. < http://www.pmb.eb.mil.br/images/documentos/abnt/abnt_05674.pdf $>$.

Brasil. (1993). Decreto-Lei No 8.666 De 21 De Junho De 1993. Regulamenta O Art. 37, Inciso Xxi, Da Constituição Federal, Institui Normas Para Licitações E Contratos Da Administração Pública E Dá Outras Providências. < HTTP://WWW.PLANALTO.GOV.BR/CCIVIL_03/LEIS/L8666CONS.HTM>.

Brasil. (2014). Tribunal de Contas da União. Obras Públicas: Recomendações Básicas para Contratação e Fiscalização de Obras de Edificações Públicas. $4^{a}$ Edição. Brasília, 2014. <https://portal.tcu.gov.br/biblioteca-digital/obras-publicas-recomendacoes-basicas-para-a-contratacao-e-fiscalizacao-de-obras-eedificacoes-publicas.htm>.

Brasil. (2021). De c r e to - Lei $n^{\circ}$ 14.133, de 1 de abril de 2021, estabelece normas gerais de licitação e contratação para as Administrações Públicas diretas, autárquicas e fundacionais da União, dos Estados, do Distrito Federal e dos Municípios. Disponível em:<http://www.planalto.gov.br/ccivil_03/_Ato2019-2022/2021/Lei/L14133.htm>.

Campos, A. T., Silva, G. \& Silva, S. W. (2019). Universidade corporativa bombeiro militar: uma realidade plausível?. Revista da Universidade Vale do Rio Verde, 17(1).

Carvalho, m. T. M., Paula, j. M. P. \& Gonçalves, p. H. (2017). Gerenciamento de obras públicas e as políticas de infraestrutura do brasil contemporâneo. Instituto de pesquisa econômica aplicada - ipea. http://repositorio.ipea.gov.br/bitstream/11058/8555/1/gerenciamento.pdf.

Cbmto. (2021). Quem somos. Bombeiros. To.gov.br. Palmas, 2021. https://www.to.gov.br/bombeiros/quem-somos/1ujwksrad6na. Acessado em: 10 mai. 2021.

Cge-AC. (2014). Controladoria Geral do Estado do Acre. Formação de Projeto Básico/Executivo: Obras e serviços de engenharia: elementos necessários e grau de precisão do orçamento. $1^{\text {a }}$ Edição. Rio Branco.

Cge-PB. (2014). Controladoria Geral do Estado da Paraíba. Manual Orientativo de Fiscalização de Obras e Serviços de Engenharia. João Pessoa. Disponível em:http://www.cge.pb.gov.br/gea/downloads/arquivos/ManualObras/manual/MANUAL\%20DE\%20FISCALIZAÇÃO\%20DE\%20OBRAS\%20v1.pdf >.

Cge-pi. (2011). Controladoria geral do estado do piauí, manual de orientações para execução e fiscalização de obras públicas. Teresina. <https://www.creasp.org.br/biblioteca/wpcontent/uploads/2013/03/manual\%2520de\%2520orientações\%2520para\%2520obras\%2520públicas.pdf>.

Chiaretto, S. \& Carvalho, E. R. C. (2018). A importância da educação continuada para o serviço operacional no corpo de bombeiros de Minas Gerais. Revista Metropolitana de Governança Corporativa, 3(1), 77-100.

Costa, a. F. (2013). Aspectos gerais sobre o fiscal de contratos públicos. Revista do tribunal de contas da união ed. 127. Brasília.

Lima, t. (2019). Entenda como funciona a licitação para obras públicas no brasil. https://www.sienge.com.br/blog/como-funciona-a-licitacao-para-obraspublicas-no-brasil/.

Meirelles, h. L., burle f. \& josé, e. (2016). Direito administrativo brasileiro (42a ed.), Até a emenda constitucional 90, de 15.9.2015. malheiros

Nagalli, A. (2016). Gerenciamento de resíduos sólidos na construção civil. Oficina de Textos.

Pires, d. L. (2014). Aplicação de técnicas de controle e planejamento em edificações. Universidade federal de minas gerais. http://pos.demc.ufmg.br/novocecc/trabalhos/pg3/113.pdf

RBF. (2014). Receita federal do brasil. Noções prévias de fiscalização de projeto e obras. Edição única.

Rodrigues, c. S. (2017). O poder-dever da administração pública na fiscalização de contratos de obras e serviços de engenharia. Revista âmbito jurídico ${ }^{\circ}$ 167 . São paulo. https://ambitojuridico.com.br/cadernos/direito-administrativo/o-poder-dever-da-administracao-publica-na-fiscalizacao-de-contratos-de-obrase-servicos-de-engenharia/

Silva, T. S., dos Santos, C. C. L., Lima, P. S. E. \& de Souza, J. J. N. (2021). Emissão de gases poluentes na construção civil: tema gerador para integração curricular. Research, Society and Development, 10(16), e343101623728-e343101623728

Siqueira, R. A. (2021). Criação de biblioteca digital como meio de universalização da informação, no âmbito do corpo de bombeiros militar de pernambuco. Revista Ibero-Americana de Humanidades, Ciências e Educação, 7(9), 246-260. 